\title{
AUGMENTED REALITY FOR ENABLING UN- AND UNDER-TRAINED INDIVIDUALS TO COMPLETE SPECIALTY CONSTRUCTION TASKS
}

SUBMITTED: November 2019

REVISED: April 2021

PUBLISHED: April 2021

EDITOR: Bimal Kumar

DOI: $10.36680 /$ j.itcon.2021.008

Jad Chalhoub, Ph.D., BIM Technology Implementation Lead, Rosendin; jchalhoub@rosendin.com

Steven K. Ayer, Ph.D., Associate Professor, Arizona State University; sayer@asu.edu

Samuel T. Ariaratnam, Ph.D., Professor, Arizona State University; samel.ariaratnam@asu.edu

SUMMARY: The construction industry is facing a severe labor shortage that is threatening the performance of projects around the world. Advanced technologies may be able to alleviate the effects of this labor cliff. Specifically, Augmented Reality (AR) has been shown to enhance the performance of current industry professionals completing different construction tasks and is also being explored as a learning tool for students and technicians alike. This research studies if AR can be used as a tool to enable untrained individuals to complete construction tasks. Three groups were identified for this research: construction professionals, construction students, and individuals with no construction experience. All three groups completed two construction tasks with $A R$, including the assembly of prefabricated electrical conduit and the layout of electrical devices in a room. The results show that all three groups completed the task in statistically similar times; however, the work of individuals with no construction experience had significantly lower accuracy during the electrical device layout task. These results suggest that construction companies may be able to leverage untrained individuals to perform certain construction tasks with AR, enabling trained and experienced professionals to focus on more challenging tasks.

KEYWORDS: Augmented Reality, HoloLens

REFERENCE: Jad Chalhoub, Steven K. Ayer, Samuel T. Ariaratnam (2021). Augmented reality for enabling unand under-trained individuals to complete specialty construction tasks. Journal of Information Technology in Construction (ITcon), Vol. 26, pg. 128-143, DOI: 10.36680/j.itcon.2021.008

COPYRIGHT: ( 2021 The author(s). This is an open access article distributed under the terms of the Creative Commons Attribution 4.0 International (https://creativecommons.org/licenses/by/4.0/), which permits unrestricted use, distribution, and reproduction in any medium, provided the original work is properly cited. 


\section{INTRODUCTION}

Construction is one of the largest industries in the United States, contributing to $4.4 \%$ of the Gross Domestic Product (GDP) of the nation (U.S. Department of Commerce, 2017). The construction industry grew from an estimated \$640 Billion income in 2014 to \$781 Billion in 2017 (U.S. Department of Commerce, 2017). It currently employs more than 7.7 million workers (Bureau of Labor Statistics, 2020) and is expected to require an additional 807,000 workers by 2028 (Office of Occupational Statistics and Employment Projections, 2018). However, this industry has been prone to a cyclical workforce shortage problem. First spotted in the 1980's (Castañeda et al., 2005), the severity of the labor shortage has increased over the past few years (Karimi et al., 2016), further underlining the importance of increasing labor attraction to the industry.

The construction industry has been historically criticized for low labor productivity (Fulford and Standing, 2014). Specifically, the value added per worker-hour has been steadily declining over the past few decades, especially when compared to other, non-farming industries such as manufacturing (Teicholz, 2013). The combination of these two trends poses a major challenge to the construction industry and highlights the need for the industry to improve its productivity, while also mitigating challenges related to labor shortages.

The use of emerging technologies may address part of this industry-wide problem. For example, new technologies may be able to replace human labor by using more efficient machinery and automation (Bock, 2015). Alternately, new technologies may also be able to increase the ability of workers, thereby leading to higher efficiency and reduced rework (Kumar et al., 2016) and can facilitate labor training processes (Lin et al., 2018). One such technology is Augmented Reality (AR), which superimposes virtual information on top of a user's view of a physical space (Milgram and Kishino, 1994). This superimposition of virtual content onto the real environment may provide a more intuitive mode of design communication than traditional 2D drawings or "blueprints", which have been the standard mode of construction communication for years.

In recent studies, AR has demonstrated its potential to increase the productivity of practitioners when used as the main design communication tool for select construction (Chalhoub and Ayer, 2018b) and pre-construction tasks (Chalhoub and Ayer, 2018a). However, the use of AR as a tool to be used by novices to immediately enable them to perform a construction task that they did not previously practice has yet to be studied. It is possible that this immersive mode of interaction may support design comprehension among untrained participants to allow them to accurately complete some construction tasks that traditionally required professional training. Therefore, the intellectual contribution of this paper is in empirically demonstrating the feasibility of current generation AR technology to support design comprehension among laypersons to complete construction tasks. This understanding provides a potential process to target groups of individuals who had traditionally been overlooked for construction positions because of lack of discipline-specific knowledge.

In order to explore this broad topic, this paper addresses two specific research questions: 1) Can individuals without any prior construction experience perform basic construction tasks correctly using AR? and 2) How does the performance of the un- and under-trained individuals compare to the performance of current industry professionals? This paper addresses these questions using an experimental approach, by comparing the performance of three groups with varying levels of construction education and training completing select construction tasks using a 3D model viewed through an AR headset. The findings will enable construction managers to explore the possibility of using this type of technology to broaden the population of individuals they may consider for completing construction tasks. By considering individuals with less experience than had traditionally been considered, companies may be able to define technologically supported workflows that allow them to better utilize their current experienced workforce to complete more challenging tasks that are not realistic to task to an inexperienced individual.

\section{BACKGROUND AND LITERATURE REVIEW}

\subsection{Training and labor shortage}

Lack of skills and training among construction workers can lead to schedule and budget overruns (Karimi et al., 2017). Historically, having trained workers has increased productivity rates compared to untrained workers, but it adversely affects the profitability of a given project (Addison and Hirsch, 1989; Lu et al., 2010). The skills learned through training are advantageous to the workers' performance, but the increased salaries demanded by these highly skilled individuals can negatively affect their employer. 
However, trained labor is still needed on the job site, especially to complete highly technical work. In fact, the lack of proper training is considered to be one of the two main causes for long term construction labor shortages (Castañeda et al., 2005; Albattah et al., 2015). Furthermore, research indicates that, even when proper training is offered, there is a high level of apprenticeship dropout rates (Mitchell and Quirk, 2005; Watson, 2012). Coupled with an aging workforce (Toossi, 2015), electricians and other trade labor groups are already experiencing severe, training-related, labor shortages (Albattah et al., 2015). These trends indicate a major labor shortage in the construction industry as a whole, and also in electrical construction specifically. Therefore, these trends highlight the opportunity for enabling un- and under-trained labor to perform certain basic tasks to ensure that trained professionals can focus on more technically challenging tasks.

\subsection{Building Information Modelling}

Building information modelling (BIM) is the development of a 3D virtual design containing both physical and informational aspects of a project (Lee et al., 2006). The construction industry has been increasingly adopting BIM, especially among contractors (McGraw-Hill Construction, 2014). Research has also demonstrated the potential for BIM to support design visualization and interaction for Architects (Yan et al., 2011). Furthermore, with increasingly powerful mobile and tablet-based computers, BIM can be used on site for model visualization and job progress documentation (Davies and Harty, 2013). On the other hand, advanced technologies, such as Augmented Reality, enable photorealistic onsite visualization of the model (Wang and Love, 2012). The continued expansion of the use of BIM in the industry provides a wealth of 3D content that may be further leveraged using emerging visualization technologies. In this paper, the authors discuss leveraging the 3D content generated for an industry standard BIM to view in an Augmented Reality environment.

\subsection{Augmented Reality}

Milgram and Kishino defined Augmented Reality (AR) as a subset of Mixed Reality (MR), where some virtual content is overlaid on a predominantly real view (Milgram and Kishino, 1994). Various efforts have been made to facilitate the migration of BIM content to an AR environment (Williams et al., 2015), enabling numerous applications in the industry. AR may be used to visualize BIM objects hidden behind walls (Thomas and Sandor, 2009) or planned improvements in space (Thomas et al., 2000). AR was also used for site monitoring and documentation (Zollmann et al., 2014), reducing site risk factors (Tatić and Tešić, 2017) and providing contextually aware safety instructions (Guo et al., 2017). These works illustrate the potential for AR to offer value to design and construction applications when used by practitioners and users with domain-specific expertise.

AR use for training and education has been explored in construction and other industries. For example, it was shown that using AR for extended training procedures reduces stress compared to traditional training methods (Tumler et al., 2008). Furthermore, AR has been used by the military to train mechanics on performing repairs by supplying relevant contextual information (Henderson and Feiner, 2009) and it may be useful for maintenance and assembly related tasks (Webel et al., 2013). In construction education, AR helps the students better achieve their learning objectives compared to traditional teaching methods (Lin et al., 2013) and has a significant positive impact on a student's learning, both in the short term and long term (Shirazi and Behzadan, 2015). For example, AR helped enhance the understanding of three dimensional objects among students (Dünser et al., 2006) and was used to teach the students about the relationship between 3D objects and their 2D projections in engineering graphics classes (Chen et al., 2011). AR also enables construction students to better understand the construction site through site condition simulation in a classroom environment (Mutis and Issa, 2014; Shanbari et al., 2016). As AR technology continues to mature, researchers continue to study potential industrial applications. This paper studies the use of AR as a tool enabling untrained individuals to complete select construction tasks.

\subsection{Previous Research}

The researchers have previously compared the performance of experienced practitioners completing a conduit assembly task (Chalhoub and Ayer, 2017) and an electrical point layout task (Chalhoub and Ayer, 2019a, 2019b) using AR and using traditional construction plans. While this current paper explores the same tasks, it uses a different sample set of participants without the experience levels possessed by participants in prior papers. As a result, the findings help to enable comparisons of un- and under-trained individuals to current practitioners. The following paragraphs detail the workflows involved in the prior research that will also be leveraged by participants in the work presented in this paper. 
During the conduit assembly task, the researchers received two similar electrical conduit models from a partner company and loaded their corresponding models on an AR head-mounted display (HMD). Practitioners from the partner company attempted to assemble the prefabricated conduits. In one treatment group, the practitioners used standard paper plan documentation. In the other treatment group, they used AR. The results revealed that using AR reduced assembly time by $45 \%$ and assembly mistakes by $75 \%$ (Chalhoub and Ayer, 2018b). The results also showed that practitioners with less experience performed worse when using traditional 2D paper plans when compared to the rest of the group, but performed better when using AR (Chalhoub and Ayer, 2018b).

The trained industry professionals performed the conduit assembly and point layout tasks better when using AR as the primary information delivery tool compared to their performance completing the tasks with the standard 2D paper plans. Since AR has already shown significant performance gains to professionals, the authors wanted to explore whether prior construction training, experience, or education are needed to enable the performance gains, or if users with no construction training or experience can perform at similar levels as experienced practitioners when using AR to complete these key construction tasks. Given that the prior work established that using AR enables better performance than using paper plans in some construction tasks, enabling untrained users to perform tasks at similar levels as professionals using AR would provide an empirical basis to justify the use of AR as a tool to enable un- and under-trained individuals to be able to fill construction roles completing specific tasks with minimal instruction, which in turn allows fully trained construction professionals to focus on the more challenging aspects of the construction process.

\section{METHODS}

The aim of this paper is to explore whether un- and under-trained individuals can perform construction tasks when using AR as the primary information delivery tool. In order to provide context to their performance, the results obtained were compared to the performance of trained and experienced professionals using the same AR interface. The following sections describe the methods used in these experiments.

\subsection{Test Subjects}

In order to assess the effectiveness of using AR for supporting basic construction activities, an experiment was run with participants from three groups: 1) experienced industry professionals, whose performance was previously tested; 2) current students studying construction management; and 3) participants with no construction education or experience.

The industry professionals involved in this work consisted of current electricians with varying levels of experience. This group had experience completing electrical construction-related tasks using traditional design communication tools including 2D construction plans and Building Information Models (BIM). Since this is the group currently doing the work, its performance was chosen to act as a benchmark against which the performance of other groups will be compared.

The construction management students were recruited from the Del E. Webb School of Construction at Arizona State University. These students did not generally have substantial construction industry experience, but they have completed several years of construction coursework as well as two mandatory field internships. This group was considered to test whether some education and construction knowledge was required to reap the benefits of using $\mathrm{AR}$ as the main design communication method for some construction tasks.

The third group included participants recruited from Arizona State University who self-declared that they had no construction experience or related education. This group was selected to test whether able bodied individuals without any construction experience could complete the construction tasks when using AR, regardless of their background or skills. While some of the participants from the third group were pursuing college degrees, their education was unrelated to construction. According to (Dunston and Wang, 2011), construction tasks may be divided into a five level hierarchical system, starting with primitive tasks, such as grasping and reaching, then composite tasks, such as moving a conduit or driving in a nail, followed by more complex tasks. For this experiment, the tasks required are within the first two levels, both of which are not taught specifically to college students. Prior to starting the activity, the researchers asked the participants whether they were capable of performing the basic tasks required to complete the activities required, such as using a screwdriver, moving large pieces of conduit, and using adhesive tape. 


\subsection{Activities}

Two basic construction activities were identified for this research: 1) conduit assembly and 2) point layout. Assembly is the act of joining pieces together to create an intended design and is primarily used in conjunction with prefabrication. Prefabrication is a construction technique where different pieces are prepared offsite and assembled on site. For electrical conduit prefabrication, all the pieces are pre-cut and bent in a shop, and the finished pieces are shipped to the jobsite where they are subsequently assembled according to the intended design for field installation. Prefabrication has been on the rise in construction, especially in electrical and mechanical construction (Khanzode et al., 2007; Karunaratne, 2011). Point layout is the act of identifying relevant points in space on a construction site. Point layout is an essential task for surveying, electrical, mechanical and other specialty construction. Both tasks are applied in a variety of construction related contexts, making them essential knowledge for potential construction professionals.

\subsection{Setup of Augmented Reality Environment}

The Microsoft HoloLens was used for AR visualization in this experiment. The HoloLens is an AR-capable HMD with inward facing projectors and a transparent visor that enables users to see the real environment around them with virtual content overlaid without requiring them to view this content through a traditional computer screen. The virtual content overlaid in the view behaves similarly to real objects. For example, if a virtual object is placed on the ground, it stays there when the user moves around the room. The HoloLens is also self-contained, so that the users can move freely around the space without requiring a wired connection to computers or other hardware. For each activity, a separate AR environment was generated. Both environments are based on an industry standard BIM at a Level Of Development (LOD) 350, where the model represents an accurate placement of the content, such as the electrical components to be built, walls, studs and other presented building elements. The models were initially created in Autodesk Revit, and exported to an FBX file, which is a generic 3D file format. Then, the models were exported to the AR headset using the Unity Game Engine.

For the conduit assembly activity, the conduit design was modelled in a BIM software by a partner company following their typical workflow procedures. The model shows the conduit with numbers next to each piece. The numbers serve as identifiers for each piece and the actual conduit pieces are tagged with the same numbers. The model was then exported to the AR environment without any alteration. The AR environment depicts the conduit at full scale, placed on the ground in its intended location in the room. Figure 1 shows the model as seen using AR with a few pieces being built.

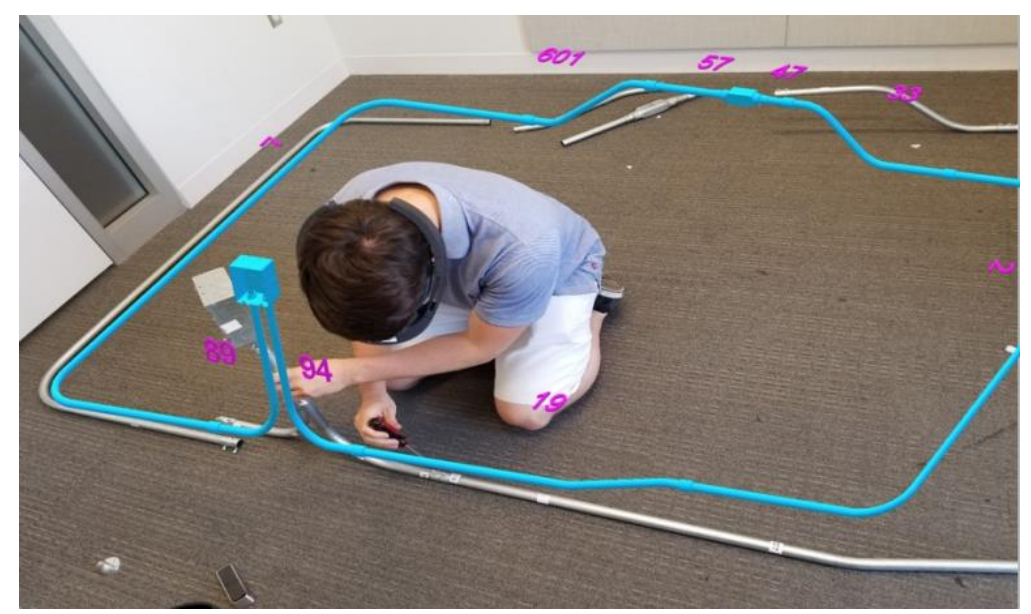

Figure 1: Participant assembling the electrical conduit with the virtual model added to the view (in blue)

For the point layout activity, a corner of a room with the points indicating the location of electrical outlets was modelled. The researchers removed all of the non-required elements from the model including walls, ceilings, floors, doors and other elements. The only elements left in the model were the electrical devices required for the activity (i.e. face plate of each device with a red cross across the middle). Additionally, the name of the device was shown on top of each plate. The model was exported from the native BIM software and into the AR environment. This enabled AR users to see full-scale models showing outlets on the walls in the room, based on the BIM. Figure 2 shows the view of the room with the virtual outlets from the perspective of a participant. 


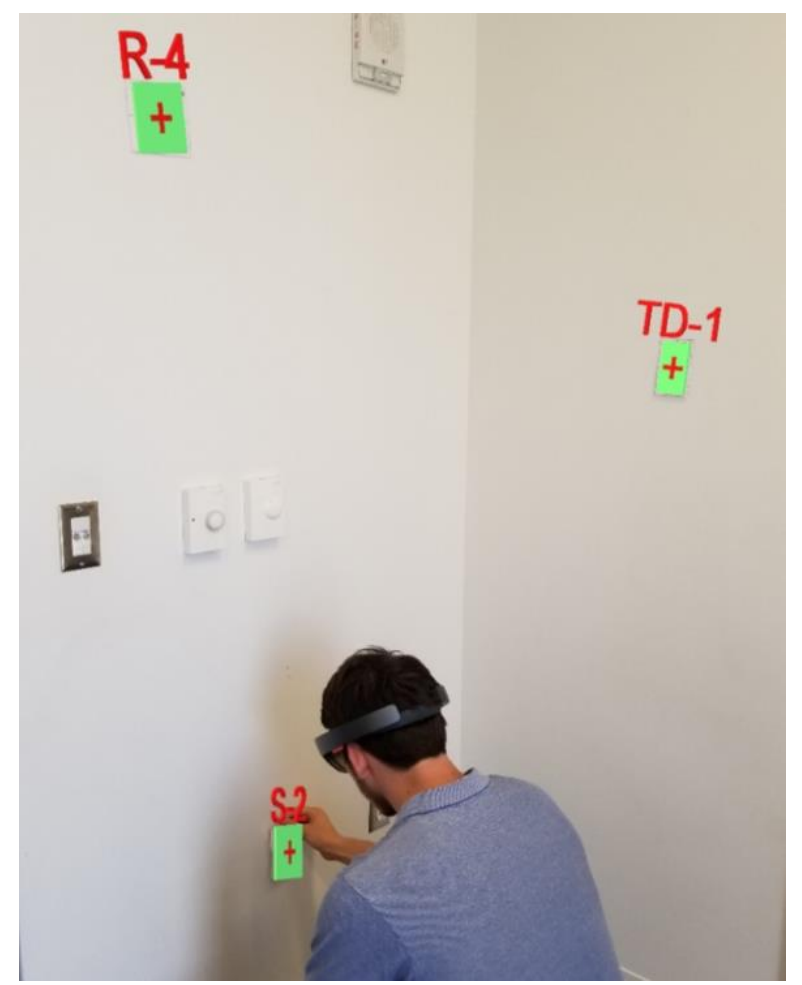

Figure 2: Participant laying out electrical devices with the virtual points shown on the walls around him

\subsection{Experimental Procedure}

The experiment took place over several days in the same room with the same materials to accommodate the sample size of participants. However, each participant completed the entirety of the activities in one session in one day. Upon arriving at the activity location, participants were provided with the AR HMD and were given a brief introduction to the tasks that they were asked to complete. Prior to the experiment, all participants were asked to complete a pre-session questionnaire. The questionnaire captured relevant background data, construction experience, age, current position, and an indication whether they had previously used AR.

After completing the pre-activity questionnaires and forms, the researchers briefed the participants on the tasks they were required to complete using a pre-defined script. The tasks were explained orally to each participant using the same, previously developed script, and the researchers answered all the questions from the participants until they stated that they understood how to complete the task. The construction student participants and nonconstruction participants completed the conduit assembly task first and then proceeded to complete the point layout task. The construction industry professionals' data was collected through two separate data collection activities with two separate companies. As a result, each practitioner participant completed only one of the two tasks, but still completed similar pre- and post- activity questionnaires to provide their perception feedback.

For all participants completing the conduit assembly task, researchers video recorded the entire assembly process. Participants were assisted in wearing the headset, loading the model, and the researchers checked that each participant could clearly see the model on the ground. For each participant, the time required to assemble the conduit, starting from the moment the participant wore the headset to the moment the participant self-declared he or she were done with the assembly task, and whether the conduit was correctly assembled were recorded.

For all participants completing the point layout task, researchers also video recorded participants to support timebased analyses after data collection. Similar to the conduit assembly timing, the point layout timing spanned from the moment the participant put on the headset to the moment he or she finished the task. Additionally, high accuracy laser tape measures, reported to be accurate to one $\mathrm{mm}$, were used to calculate actual distances for each laid out point as shown in Figure 3. Research assistants measured the distances between the centers of the adhesive notes and known points in the room (i.e. distances to adjacent walls or to the floor) between each layout design. This provided accurate coordinates to support subsequent analyses related to accuracy of the laid-out points. 


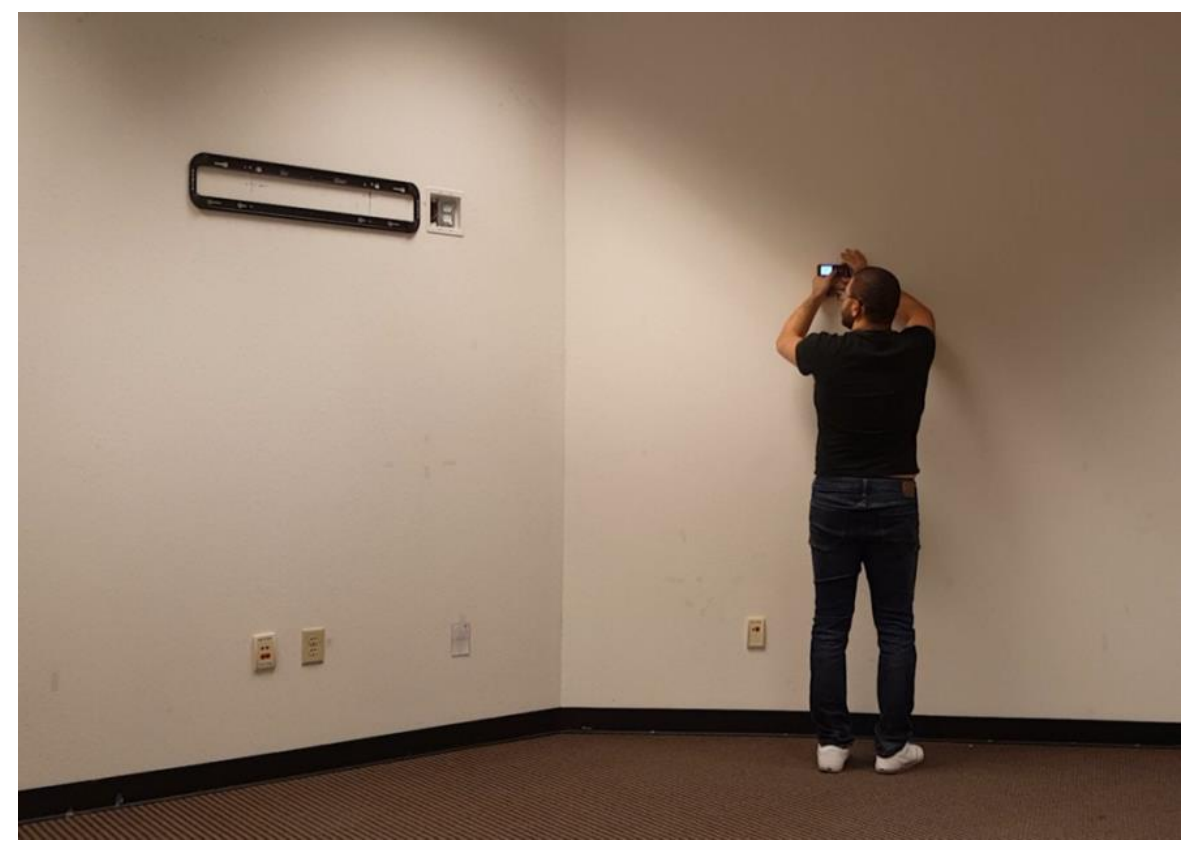

Figure 3: researchers measuring point offsets of points laid out

The goal of the research is to understand whether AR can enable the same performance gains in un- and undertrained users compared to experienced, trained practitioners. Therefore, task-specific performance metrics were measured to enable this comparison. Specific metrics included time and number of mistakes for the conduit assembly task, and time and accuracy for the point layout task. These metrics provide relevant data to assess performance for this research, but they also yield findings that may be directly compared to existing performance data for other construction applications in order to assess the potential of AR to support the performance of less experienced labor.

When all point layout and conduit construction activities were completed, participants were presented with a postsession questionnaire. This questionnaire contained multiple choice questions pertaining to the use of AR and their perception of the activities. Furthermore, open-ended questions to solicit their perceptions regarding their favorite and least favorite aspects of the exercise were administered. The specific question text used to elicit this feedback is presented in the results section along with the related findings.

\section{RESULTS}

\subsection{General}

Ninety-one individuals participated in the experiment. Table 1 illustrates the specific numbers of participants who completed each task. Participants' ages ranged between industry practitioner participants (21-59 years old), construction management students (22-30 years old), and non-construction related participants (20-28 years old). The industry participants included journeymen electricians, foremen, modelers, coordinators and construction managers. Table 2 summarizes whether the participants had laid out points or assembled conduits during the last year and their total years of construction experience. The results related to performance of these participants are organized in the following sections according to the different construction tasks studied.

Table 1: Numbers of participants completing each task

\begin{tabular}{lll}
\hline Group & Conduit Assembly & Point Layout \\
\hline Industry Professionals & 18 & 28 \\
\hline Construction Students & 18 & 21 \\
\hline Non-Construction group & 21 & 21 \\
\hline Total & 57 & 70 \\
\hline
\end{tabular}


Table 2: Experience of industry participants

\begin{tabular}{llll}
\hline \multirow{2}{*}{ Years of Experience } & \multicolumn{2}{l}{ Laid out Points / Assembled Conduit last year } & \multirow{2}{*}{ Total } \\
\cline { 2 - 3 } & Yes & No & \\
\hline Less than 1 year & $9 \%(\mathrm{n}=4)$ & $11 \%(\mathrm{n}=5)$ & $20 \%(\mathrm{n}=9)$ \\
\hline $\mathbf{1}$ to 5 years & $22 \%(\mathrm{n}=10)$ & $7 \%(\mathrm{n}=3)$ & $29 \%(\mathrm{n}=13)$ \\
\hline 6 to 10 years & $11 \%(\mathrm{n}=5)$ & $11 \%(\mathrm{n}=5)$ & $22 \%(\mathrm{n}=10)$ \\
\hline more than 10 years & $17 \%(\mathrm{n}=8)$ & $13 \%(\mathrm{n}=6)$ & $30 \%(\mathrm{n}=14)$ \\
\hline Total & $59 \%(\mathrm{n}=27)$ & $41 \%(\mathrm{n}=19)$ & $100 \%(\mathrm{n}=46)$ \\
\hline
\end{tabular}

\subsection{Conduit assembly}

All participants, from all three groups, were able to complete the assembly of the conduit, but not all of the assemblies were "correct". An assembled conduit was considered "incorrect" when the orientation or placement of at least one piece was wrong. For example, if a piece of conduit was supposed to be installed perpendicular to the ground, but was installed flat on the ground, the conduit would require rework, and was considered incorrect. Table 3 summarizes the overall performance of the three groups in the conduit assembly and presents the results of the Shapiro-Wilk test of normality related to the assembly times. On average, the assembly time varied between 275 seconds and 300 seconds, and the percentage correctness varied between $61 \%$ and $89 \%$. The Shapiro-Wilk test of normality had a significance of less than 0.05 for all three groups. Thus, the null hypothesis is rejected and the groups are not normally distributed.

Table 3: Average performance of each group in the conduit assembly task and corresponding results of the Shapiro-Wilk test of Normality

\begin{tabular}{llll}
\hline Group & Assembly Time (seconds) & Shapiro-Wilk Test (p-value) & Percentage Correct \\
\hline Industry Professionals & 284.94 & $0.005^{*}$ & $89 \%$ \\
\hline Construction Students & 299.59 & $0.006^{*}$ & $61 \%$ \\
\hline Non-Construction group & 275.86 & $0.000^{*}$ & $71 \%$ \\
\hline
\end{tabular}

*Indicates groups are not normally distributed at 0.05 significance level

Conduit correctness is a categorical variable, and statistical significance was tested using a cross-tabulation chisquare approach, presented in Table 4. According to the Chi-Square test (p-value > 0.05), the levels of correctness of the assembly between the different groups is not statistically significant. While this indicates that, statistically, all groups are equally likely to assemble the prefabricated conduit correctly when using AR, the differences in correctness are not inconsequential: in fact, the variation of percentage of correctness (89\% to 61\%) highlights the importance of having an experienced construction professional supervision to ensure that the quality of the assembled conduit is acceptable and consistent.

Table 4: Summary of the cross-tabulation and Pearson Chi-Square test results

\begin{tabular}{|c|c|c|c|c|c|c|}
\hline \multirow[t]{2}{*}{ Groups } & \multirow{2}{*}{$\begin{array}{l}\text { Count, } \% \\
\text { Deviation }\end{array}$} & \multirow[t]{2}{*}{ Within } & \multicolumn{2}{|c|}{ Correct Conduit Build } & \multirow[t]{2}{*}{ Total } & \multirow{2}{*}{$\begin{array}{l}\text { Pearson Chi- } \\
\text { Square P-Value }\end{array}$} \\
\hline & & & Incorrect & Correct & & \\
\hline \multirow{2}{*}{$\begin{array}{l}\text { Industry } \\
\text { Professionals }\end{array}$} & Count & & 2 & 16 & 18 & \multirow{6}{*}{0.16} \\
\hline & $\%$ Within Group & & $11.1 \%$ & $88.9 \%$ & $100.0 \%$ & \\
\hline \multirow{2}{*}{$\begin{array}{l}\text { Construction } \\
\text { Students }\end{array}$} & Count & & 7 & 11 & 18 & \\
\hline & $\%$ Within Deviatio & & $38.9 \%$ & $61.1 \%$ & $100.0 \%$ & \\
\hline \multirow{2}{*}{$\begin{array}{l}\text { Non-Construction } \\
\text { Group }\end{array}$} & Count & & 6 & 15 & 21 & \\
\hline & $\%$ Within Deviatio & & $28.6 \%$ & $71.4 \%$ & $100.0 \%$ & \\
\hline
\end{tabular}

The Shapiro-Wilk test of normality was used on all the conduit assembly data sets, and none were normally distributed, thus the non-parametric Kruskal-Wallis test was used to compare the samples. Table 5 presents the results of the Kruskal-Wallis test. There was no evidence to suggest that the performance of the groups was 
significantly different ( $\mathrm{p}$-value $=0.435>0.05$ ). In terms of correctness and speed of conduit assembly task when using AR, there were no statistically significant differences between the three groups.

Table 5: Results of the Kruskal-Wallis test for the conduit assembly time

\begin{tabular}{lllll}
\hline Testing & Total N & Test Statistic & Degrees of Freedom & P-value \\
\hline Conduit Assembly Time & 57 & 1.666 & 2 & 0.435 \\
\hline
\end{tabular}

\subsection{Layout}

All participants successfully laid out the electrical devices in the room, placing the adhesive note corresponding to the intended electrical device in the correct general area on the walls. The time required to layout the space and the accuracy of each laid-out point were compared. The accuracy was further divided into vertical accuracy and horizontal accuracy. Table 6 presents the results of the performances of participants from the three groups and the corresponding normality tests. For all but two of the test groups, the p-value for the Shapiro-Wilk test of normality is less than 0.05 , indicating that the groups are not normally distributed.

Table 6: Average performance of each group in the point layout task and corresponding results of the ShapiroWilk test of normality

\begin{tabular}{|c|c|c|c|c|c|c|}
\hline Groups & $\begin{array}{l}\text { Layout Time } \\
\text { (seconds) }\end{array}$ & $\begin{array}{l}\text { Shapiro-Wilk } \\
\text { Test (p-value) }\end{array}$ & $\begin{array}{l}\text { Average Absolute } \\
\text { Vertical } \\
\text { Accuracy (meter) }\end{array}$ & $\begin{array}{l}\text { Shapiro- } \\
\text { Wilk Test } \\
\text { (p-value) }\end{array}$ & $\begin{array}{l}\text { Average Absolute } \\
\text { Horizontal } \\
\text { Accuracy (meter) }\end{array}$ & $\begin{array}{l}\text { Shapiro-Wilk } \\
\text { Test (p-value) }\end{array}$ \\
\hline Industry & 164.38 & 0.006 & & $0.000 *$ & & $0.000 *$ \\
\hline Professionals & & & 0.027 & & 0.038 & \\
\hline Construction & 114.42 & 0.005 & & $0.000 *$ & & $0.000 *$ \\
\hline Students & & & 0.030 & & 0.023 & \\
\hline $\begin{array}{l}\text { Non- } \\
\text { Construction } \\
\text { group }\end{array}$ & 102.76 & 0.45 & 0.071 & 0.614 & 0.046 & $0.000^{*}$ \\
\hline
\end{tabular}

*Indicates the groups are not normal at the 0.05 significance level

Since most of the data is not normally distributed, the Kruskal-Wallis test was used to determine whether there exists a significant difference in the performances of the different groups during the layout tasks. Table 7 summarizes the results of the Kruskal-Wallis tests on layout time. The results suggest that there is a significant difference in performance between the groups ( $p$-value $<0.05$ ). A post-hoc adjusted Mann-Whitney test was used to determine the groups between which there exists a significant difference. The results of the adjusted MannWhitney post-hoc test are presented in Table 8. There only exists a difference between professional and nonconstruction participants at the $95 \%$ confidence level. Surprisingly, non-construction participants were faster, on average, than construction professionals by 61 seconds.

Table 7: Summary of the Kruskal-Wallis for the time to complete the layout task between the three groups

\begin{tabular}{lllll}
\hline Testing & Total N & Test Statistic & Degrees of Freedom & P-value \\
\hline Layout Time & 70 & 6.957 & 2 & $0.031^{*}$ \\
\hline
\end{tabular}

*Indicates there exists a statistically significant difference between the compared groups at 0.05 significance level

Table 8: Post-Hoc analysis for the time required to complete the point layout task using corrected MannWhitney tests

\begin{tabular}{lllll}
\hline Group 1 & Group 2 & Mean Difference & Standard Test Statistic & Adjusted P-value \\
\hline Professionals & Construction Students & 49.95776 & 2.018 & 0.131 \\
\cline { 2 - 5 } & $\begin{array}{l}\text { Non-Construction } \\
\text { Group }\end{array}$ & $61.61824^{*}$ & 2.399 & $0.049 *$ \\
\hline Construction Students & $\begin{array}{l}\text { Non-Construction } \\
\text { Group }\end{array}$ & 11.66048 & 0.356 & 1.000 \\
\hline
\end{tabular}

*Indicates there exists a statistically significant difference between the compared groups at 0.05 significance level 
Table 9 summarizes the results of the Kruskal-Wallis test comparing the accuracies of the laid-out points by the different groups, both vertically and horizontally. The results suggest that at least one group had significantly different accuracies horizontally and vertically ( $\mathrm{p}$-value < 0.05). A post-hoc adjusted Mann-Whitney test was used to determine the groups between which there exists a significant difference. The results of the adjusted MannWhitney post-hoc test are presented in Table 10. In general, non-construction participants were found to have significantly less accuracy in point layout placement. When compared to industry professionals, non-construction participants were, on average, 0.035 meters less accurate horizontally, and 0.065 meters less accurate vertically (p-value <0.05). Furthermore, when compared to construction students, non-construction participants were 0.042 meters less accurate horizontally, and 0.058 meters less accurate vertically ( $\mathrm{p}$-value <0.05). However, there is no difference in the layout accuracy of the devices between industry professionals and construction students.

Table 9: Summary of two Kruskal-Wallis tests for the accuracy of the laid-out points along the vertical and horizontal axis

\begin{tabular}{lllll}
\hline Testing & Total N & Test Statistic & Degrees of Freedom & P-value \\
\hline Vertical Accuracy & 341 & 115.319 & 2 & $0.000^{*}$ \\
\hline Horizontal Accuracy & 341 & 34.632 & 2 & $0.000^{*}$ \\
\hline
\end{tabular}

*Indicates there exists a statistically significant difference between the compared groups at 0.05 significance level

Table 10: Adjusted Mann-Whitney post-hoc analysis for the accuracy of the laid-out points along the vertical and horizontal axis

\begin{tabular}{lllll}
\hline $\begin{array}{l}\text { Dependent } \\
\text { Variable }\end{array}$ & Group 1 & Group 2 & $\begin{array}{l}\text { Mean Difference } \\
(\text { Meter) }\end{array}$ & P-value \\
\hline \multirow{2}{*}{ Horizontal } & $\begin{array}{l}\text { Industry } \\
\text { Professionals }\end{array}$ & Construction Students & 0.007 & 0.072 \\
\cline { 2 - 5 } & $\begin{array}{l}\text { Construction } \\
\text { Students }\end{array}$ & Non-Construction Group & -0.042 & $0.000^{*}$ \\
\hline \multirow{2}{*}{ Vertical } & $\begin{array}{l}\text { Industry } \\
\text { Professionals }\end{array}$ & Construction Students & -0.007 & $0.000^{*}$ \\
\cline { 2 - 5 } & $\begin{array}{l}\text { Construction } \\
\text { Students }\end{array}$ & Non-Construction Group & -0.058 & .798 \\
\hline
\end{tabular}

*Indicates there exists a statistically significant difference between the compared groups at 0.05 significance level

\subsection{Perceptions}

At the end of the experiment, the participants filled out a post-session questionnaire. $96 \%$ of all participants indicated that it was easy to use AR to complete construction tasks, and $75 \%$ of the industry practitioners agreed that it is easier to complete the assigned construction task using AR than it is using traditional paper plans. These findings are aligned with prior studies conducted concerning the use of AR to complete construction tasks (Chalhoub and Ayer, 2018b).

In the open-ended questions, users indicated that they liked seeing the model in space, making it easier to understand and visualize the design in space. However, many participants complained that the headset can become top heavy, especially for prolonged use, which can lead to neck fatigue if used all day. Some participants also noted that the model was too bright or too dim, and others found the field of view to be too small. While all these concerns are valid, the hardware of the device is likely to continue to improve as the technology matures, leading to lighter, smaller, and more adjustable headsets. Furthermore, if the device was to be deployed at scale, training the users would enable them to easily control the settings of the device to personalized comfort levels. 


\section{DISCUSSION}

In this experiment, laypersons with no construction training were asked to complete construction-related tasks using BIM content presented in AR. The performance of these laypersons was compared to the performance of participants with discipline specific work experience and education. The overall performance of the nonconstruction participants was comparable to the performance of construction students and professionals for all tracked metrics except the accuracy of the laid-out points. For the two tested applications, the time required by non-construction participants to finish the tasks was not statistically different than the time required by trained professionals or construction students. Specifically, for the conduit assembly task, the average time required by the different groups to finish the task was within 5\% of one another, as shown in Figure 4. Furthermore, during the point layout task, non-construction participants finished the task significantly faster than professionals. The results related to use of AR by current practitioners have been established by recent literature (Chalhoub and Ayer, 2019b). However, the ability of this same technology to enable un- and under-trained individuals to complete the same tasks with AR differentiates this work from the current body of knowledge. These new results contribute key findings to a potential strategy that leverages AR to address the workforce shortages that have been reported in the construction industry (Albattah et al., 2019).

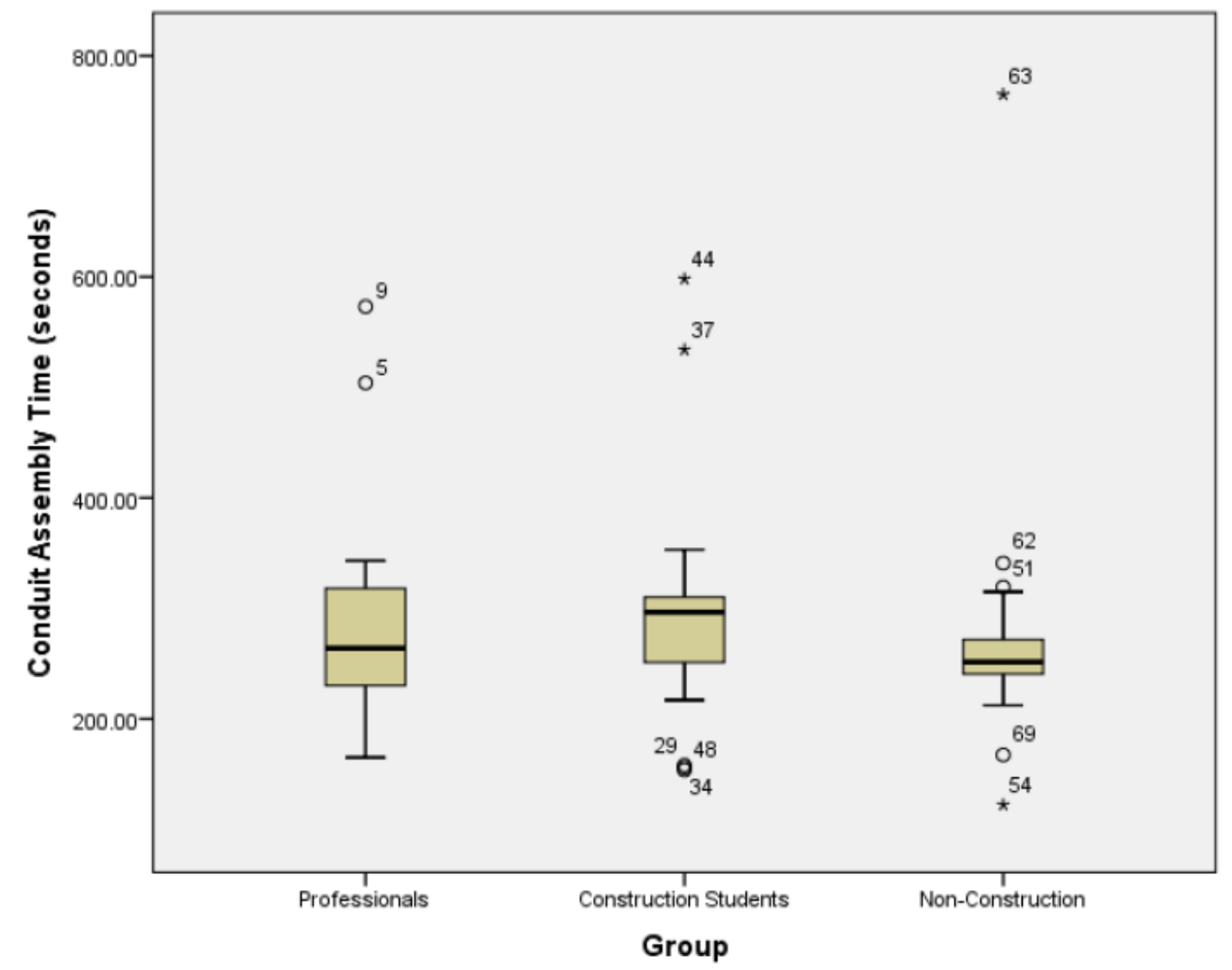

Figure 4: Box Plot of times taken to complete construction by the three groups

The only statistically significant difference in performance related to the accuracy of point layout where the average accuracy of the non-construction group was significantly lower than that of the construction professionals and construction students. One possible reason for the reduced accuracy could be the lack of understanding among participants with no construction experience related to the importance of accuracy during the layout process. This rationale is further supported when comparing results with construction students. These participants performed layout more accurately, but also did not have substantial construction layout experience. However, as construction students, they may understand the impact of layout on subsequent construction processes. This may indicate that, for the task of carefully aligning the adhesive note to the augmented BIM content, accuracy may be more relevant to construction minded students and practitioners because they understand the context in which that task is 
performed. They may also understand the consequences of inaccurate layout compared to those with no construction background. This would also explain faster performance of the non-construction students compared to construction professionals. Since they appear to pay less attention to the exact placement of the points, they tend to go through the points at a faster rate than other participants who would acknowledge the downstream effects of the point placement. If AR was to be employed by non-construction personnel for point layout, it would be important to highlight the importance of accurate placement to avoid the reduced layout accuracy.

Despite the differences in layout accuracy performance, it is worth noting that, among all participants, the placement of the points was still within $0.071 \mathrm{~m}$ vertically and $0.046 \mathrm{~m}$ horizontally. While these values are outside generally accepted tolerances, they may only indicate minimal practical effect for this type of task. For applications that require relatively low accuracy, such as the electrical layout of a residential project where devices are likely to be installed horizontally to the nearest stud and vertically based on a physical template, the "errors" in AR may be acceptable because the exact location of an eventual electrical device may not be dictated exactly by a laid out point anyway. Therefore, given the performance gains observed and the specific workflows involved in current practice, the performance of untrained individuals may not offer practical differences from trained practitioners for this type of simple task.

While prior research has shown that using more immersive, 3D modes of communication reduces cognitive workload and increases accuracy among construction practitioners completing a miniature, construction-inspired task (Dadi et al., 2014), this paper demonstrates that un- or under-trained labor using AR exhibit behaviours and performances comparable to that of trained labor using the same technology. This presents a new tool for managers to explore to support the performance of their personnel by enabling less-experienced professionals to complete certain construction tasks that had traditionally required more-experienced professionals to handle, without sacrificing performance. If this strategy was leveraged, it could potentially enable more-experienced individuals to focus on more challenging tasks that require their domain-specific expertise.

\section{LIMITATIONS}

The limitations of this work are related to the test groups, location of testing, and the time required to export BIM for AR use. This research only measured the ability of the participants to learn and perform composite tasks, and not learn new basic skills. All participants in the study had prior knowledge of moving pieces of conduit and using a screwdriver and tape. It should be noted that additional construction training would still be needed for workers to learn the use of new tools and basic skills. Additionally, it is possible that even though several of the performance metrics showed some similarities between participant groups, the ways in which those groups completed their work was not explored from a qualitative research perspective. Therefore, it is potentially possible that even if the resultant work of untrained individuals can be similar in some ways to experienced individuals, the methods for achieving those results may be significantly different. Furthermore, the authors recognize that having a different group of individuals, or having the same groups perform different sets of tasks, could have affected the results. However, the contribution of this work is not in the exact time differences reported, but rather in empirically demonstrating that a group, that would not typically be considered to complete a construction task, was successful in using AR to complete a task with a similar performance to that of trained professionals using the same technology in some cases, or with an accuracy differential that might acceptable or circumventable with minor changes to the workflow.

Additionally, some of the experienced professionals had spent prolonged periods of time without hands-on experience related to the specific construction tasks assigned. This could have a potential negative effect on their performance, especially when using traditional 2D paper plans. The authors did not account for this in the paper, but given the relatively small standard deviation within the samples, the authors do not have evidence to indicate that this had substantial impacts on their findings.

For safety reasons, the research presented was completed in controlled environments. Active construction sites may pose additional challenges for current AR technology. It is possible that additional noise, safety concerns, or other ergonomic constraints related to prolonged AR use could hinder the long-term viability of using AR on actual sites. Fortunately, as the value of AR continues to be documented by researchers, and the practical viability of the technology is studied through pilot case studies with industry, this will continue to encourage developers to enhance the technical attributes of the technology to mitigate observed practical challenges. While this future development is likely to mitigate many of the potential limitations associated with implementing AR on active 
sites, the authors recognize that the exact magnitude of implementing AR in this work might be impacted by the environment in which it is used.

The authors did not empirically test the performance of un- or under-trained personnel using traditional 2D plans. While it is theoretically possible that untrained individuals would perform these tasks as well as trained professionals, this would seem highly counterintuitive based on all of the training provided to actual practitioners when learning their trade. Furthermore, while the participants did not have relevant skills training, they are college students. The authors recognize that this sample of participants may not be representative of the general untrained workforce that the construction industry may target.

It is also important to note that while this paper empirically proves that AR can enable un- and under-trained individuals to perform select construction tasks effectively, it does not address the socio-economic factors of incorporating the hiring of these individuals to address labor shortage, and further research into these factors would be needed. In other words, it is possible that the exact population of workers who would likely be targeted by companies may fall into different socio-economic categories than the students tested in this work. While the authors maintain that the lack of construction expertise may be a hurdle that AR can help to overcome for certain tasks, they cannot make claims about the extent to which AR would mitigate other challenges related to differing socio-economic factors.

Finally, one limitation associated with AR for widespread adoption relates to the process of exporting BIM content to AR. Currently, this process of preparing content for AR is typically performed manually. While the process has been documented in several publications (Alsafouri and Ayer, 2017; Chalhoub et al., 2018), if it were to be substantially scaled up, it could require a substantial time investment. Similar to the limitations related to AR environment, this limitation related to exporting BIM content to AR will likely improve in time as more programs and add-ons become available to streamline this process.

\section{CONCLUSIONS}

This research is a novel approach to studying the use Augmented Reality (AR) in construction, by determining the performance of un- and under-trained individuals when completing construction-related tasks in comparison to well-trained professionals. Three groups of participants were identified: 1 ) construction industry practitioners; 2) construction management students; and 3) laypersons without any construction-specific training. All three groups performed two construction tasks using AR, including: 1) prefabricated conduit assembly and 2) electrical point layout. During the conduit assembly task, all participants performed similarly; however, during the point layout task, non-construction participants finished significantly faster, albeit with lower accuracy compared to construction practitioners.

While there were some differences in performance among the three groups, the similarity between them was noteworthy. Typically, new employees require between three and five years of training (Electrician School in Arizona, 2018) to be effective construction personnel. Therefore, observations related to the comparable performance of un- and under-trained participants to professionals when using AR offer insight into potential strategies that could be developed using AR to support training for construction tasks similar to those tested in this work.

Overall, the findings presented in this work provide empirical evidence of the types of performance similarities and differences that may be present among un- and under-trained individuals through the use of AR. These findings may support the development of new, AR-based, training strategies for conveying design content to new construction personnel. These new strategies may enable practitioners to introduce new hires to certain types of construction tasks where they may be able to provide value to projects with the use of AR, based on the evidence offered in this work. Furthermore, the performance results presented in this work will enable practitioners to compare anticipated performance gains for these two specific tasks, to the upfront costs associated with adopting $\mathrm{AR}$, and could be further used as a framework to test the feasibility of using AR on other tasks in the field. Ultimately, the findings produced through this work will support evidence-based decision making when defining and assessing potential strategies for using AR to enable the performance of new construction personnel. 


\section{FUNDING STATEMENT \& DATA AVAILABILITY}

This material is based upon work supported by the National Science Foundation under Grant No. IIS-1566274 and ELECTRI International.

The statistical data used to support the findings of this study are restricted by Arizona State University's Institutional Review Board and cannot be released to protect the personal information of the participants in the experiments described in this study.

\section{REFERENCES}

Addison, J. T. and Hirsch, B. T. (1989) 'Union Effects on Productivity, Profits, and Growth: Has the Long Run Arrived?', Journal of Labor Economics, 7(1), pp. 72-105. doi: 10.1086/298199.

Albattah, M. A., Goodrum, P. M. and Taylor, T. R. B. (2015) 'Demographic Influences on Construction Craft Shortages in the U.S. and Canada', in 5th International/11th Construction Specialty Conference, pp. 169-176. doi: 10.14288/1.0076372.

Albattah, M. A., Goodrum, P. M. and Taylor, T. R. B. (2019) 'New Metric of Workforce Availability among Construction Occupations and Regions', Practice Periodical on Structural Design and Construction. doi: 10.1061/(ASCE)SC.1943-5576.0000413.

Alsafouri, S. and Ayer, S. K. (2017) 'A Step-By-Step Procedure for Implementing Mixed Reality Visualization Interfaces in Design and Constructability Review Sessions', in Lean and Computing in Construction Congress - Volume 1: Proceedings of the Joint Conference on Computing in Construction, pp. 913-921. doi: 10.24928/JC3-2017/0147.

Bock, T. (2015) 'The future of construction automation: Technological disruption and the upcoming ubiquity of robotics', Automation in Construction, 59, pp. 113-121. doi: 10.1016/j.autcon.2015.07.022.

Bureau of Labor Statistics (2020) Industries at a Glance: Construction: NAICS 23. Available at: https://www.bls.gov/iag/tgs/iag23.htm (Accessed: 8 March 2020).

Castañeda, J. A., Tucker, R. L. and Haas, C. T. (2005) 'Workers' Skills and Receptiveness to Operate Under the Tier II Construction Management Strategy', Journal of Construction Engineering and Management, 131(7), pp. $799-807$. doi: 10.1061/(ASCE)0733-9364(2005)131:7(799).

Chalhoub, J., Alsafouri, S. and Ayer, S. K. (2018) 'Leveraging Site Survey Points for Mixed Reality BIM Visualization', in Construction Research Congress 2018, pp. 326-335. Available at: https://ascelibrary.org/doi/abs/10.1061/9780784481264.032 (Accessed: 5 April 2018).

Chalhoub, J. and Ayer, S. (2017) 'Mixed Reality for Electrical Prefabrication Tasks', in Computing in Civil Engineering 2017, pp. 76-83. Available at: http://ascelibrary.org/doi/abs/10.1061/9780784480847.010 (Accessed: 13 September 2017).

Chalhoub, J. and Ayer, S. K. (2018a) 'Performance effects of using Mixed Reality for electrical point layout tasks', in Amor, R. and Dimyadi, J. (eds) CONVR 2018: Evolving Construction Towards a Technological Revolution. Auckland, New Zealand: University of Auckland, pp. 103-110. doi: 978-0-473-45402-9.

Chalhoub, J. and Ayer, S. K. (2018b) 'Using Mixed Reality for electrical construction design communication', Automation in Construction, 86, pp. 1-10. doi: 10.1016/j.autcon.2017.10.028.

Chalhoub, J. and Ayer, S. K. (2019a) 'Effect of varying task attributes on augmented reality aided point layout', Journal of Information Technology in Construction.

Chalhoub, J. and Ayer, S. K. (2019b) 'Exploring the performance of an augmented reality application for construction layout tasks', Multimedia Tools and Applications. Springer US, pp. 1-24. doi: 10.1007/s11042-019-08063-5.

Chen, Y.-C. et al. (2011) 'Use of Tangible and Augmented Reality Models in Engineering Graphics Courses', Journal of Professional Issues in Engineering Education and Practice, 137(August), pp. 267-276. doi: 10.1061/(ASCE)EI.19435541.0000078.

Dadi, G. B. et al. (2014) 'Effectiveness of communication of spatial engineering information through 3D CAD and 3D printed models', Visualization in Engineering, 2(1), p. 9. doi: 10.1186/s40327-014-0009-8. 
Davies, R. and Harty, C. (2013) 'Implementing "site BIM": A case study of ICT innovation on a large hospital project', Automation in Construction, 30, pp. 15-24. doi: 10.1016/j.autcon.2012.11.024.

Dünser, A. et al. (2006) 'Virtual and Augmented Reality as Spatial Ability Training Tools', CHINZ '06 Proceedings of the 7th ACM SIGCHI New Zealand chapter's international conference on Computer-human interaction: design centered HCI, pp. 1-8. doi: 10.1145/1152760.1152776.

Dunston, P. S. and Wang, X. (2011) 'A hierarchical taxonomy of aec operations for mixed reality applications', Electronic Journal of Information Technology in Construction, 16, pp. 433-444. Available at: http://itcon.org/paper/2011/25 (Accessed: 8 August 2017).

Electrician School in Arizona (2018). Available at: https://www.electricianschooledu.org/arizona/ (Accessed: 1 November 2018).

Fulford, R. and Standing, C. (2014) 'Construction industry productivity and the potential for collaborative practice', International Journal of Project Management, 32(2), pp. 315-326. doi: 10.1016/j.ijproman.2013.05.007.

Guo, H., Yu, Y. and Skitmore, M. (2017) 'Visualization technology-based construction safety management: A review', Automation in Construction, 73, pp. 135-144. doi: 10.1016/j.autcon.2016.10.004.

Henderson, S. J. and Feiner, S. (2009) 'Evaluating the benefits of augmented reality for task localization in maintenance of an armored personnel carrier turret', in Science and Technology Proceedings - IEEE 2009 International Symposium on Mixed and Augmented Reality, ISMAR 2009, pp. 135-144. doi: 10.1109/ISMAR.2009.5336486.

Karimi, H. et al. (2016) 'Quantitative analysis of the impact of craft worker availability on construction project safety performance', Construction Innovation. Emerald Group Publishing Limited , 16(3), pp. 307-322. doi: 10.1108/CI10-2015-0050.

Karimi, H., Taylor, T. and Goodrum, P. (2017) 'Analysis of the impact of craft labour availability on North American construction project productivity and schedule performance', Management and Economics, 35(6), pp. 368-380. Available at: http://www.tandfonline.com/doi/abs/10.1080/01446193.2017.1294257 (Accessed: 14 September 2017).

Karunaratne, G. P. (2011) 'Prefabricated and electrical vertical drains for consolidation of soft clay', Geotextiles and Geomembranes, 29(4), pp. 391-401. doi: 10.1016/j.geotexmem.2010.12.005.

Khanzode, A., Fischer, M. and Reed, D. (2007) 'Challenges and benefits of implementing virtual design and construction technologies for coordination of mechanical, electrical, and plumbing systems on large healthcare project', Image Rochester NY, 5(Vdc), pp. 205-212. Available at: http://www.irbnet.de/daten/iconda/CIB21498.pdf (Accessed: 22 March 2017).

Kumar, V. R. P., Balasubramanian, M. and Jagadish Raj, S. (2016) 'Robotics in construction industry', Indian Journal of Science and Technology, 9(23). doi: 10.17485/ijst/2016/v9i23/95974.

Lee, G., Sacks, R. and Eastman, C. M. (2006) 'Specifying parametric building object behavior (BOB) for a building information modeling system', Automation in Construction, 15(6), pp. 758-776. doi: 10.1016/j.autcon.2005.09.009.

Lin, K.-Y. et al. (2018) 'Training of Low-Literacy and Low-English-Proficiency Hispanic Workers on Construction Fall Fatality', Journal of Management in Engineering, 34(2), p. 05017009. doi: 10.1061/(ASCE)ME.1943-5479.0000573.

Lin, T. J. et al. (2013) 'An investigation of learners' collaborative knowledge construction performances and behavior patterns in an augmented reality simulation system', Computers and Education, 68, pp. 314-321. doi: 10.1016/j.compedu.2013.05.011.

Lu, Y., Tao, Z. and Wang, Y. (2010) 'Union effects on performance and employment relations: Evidence from China', China Economic Review. North-Holland, 21(1), pp. 202-210. doi: 10.1016/j.chieco.2010.01.001.

McGraw-Hill Construction (2014) The Business Value of BIM for Construction in Major GLobal Markets: How contractors around the world are driving innovation with Building Information Modeling, SmartMarket Report. Available at: http://static-dc.autodesk.net/content/dam/autodesk/www/solutions/building-informationmodeling/construction/business-value-of-bim-for-construction-in-global-markets.pdf.

Milgram, P. and Kishino, F. (1994) 'Taxonomy of mixed reality visual displays', IEICE Transactions on Information and Systems, E77-D(12), pp. 1321-1329. doi: 10.1.1.102.4646. 
Mitchell, W. and Quirk, V. (2005) 'Skills shortages in Australia: concepts and reality', Creating a Culture of Full Employment: Incorporating the 7th Path to Full Employment Conference and 12th National Conference on Unemployment, pp. 303-327. Available at: https://search.informit.com.au/documentSummary;dn=138827989867879;res=IELHSS (Accessed: 22 September 2017).

Mutis, I. and Issa, R. R. A. (2014) 'Enhancing Spatial and Temporal Cognitive Ability in Construction Education Through Augmented Reality and Artificial Visualizations', in Computing in Civil and Building Engineering (2014), pp. 20792086. doi: $10.1061 / 9780784413616.258$.

Office of Occupational Statistics and Employment Projections (2015) Employment Projections: 2014-24 Summary, Bureau of Labor Statistics. Available at: https://www.bls.gov/news.release/ecopro.nr0.htm (Accessed: 14 September 2017).

Shanbari, H., Blinn, N. and Issa, R. R. A. (2016) 'Using augmented reality video in enhancing masonry and roof component comprehension for construction management students', Engineering, Construction and Architectural Management, 23(6), pp. 765-781. doi: 10.1108/ECAM-01-2016-0028.

Shirazi, A. and Behzadan, A. H. (2015) 'Design and assessment of a mobile Augmented Reality-based information delivery tool for construction and civil engineering curriculum', Journal of Professional Issues in Engineering Education and Practice, 141(3), pp. 235-243. doi: 10.1061/(ASCE)EI.1943-5541.

Tatić, D. and Tešić, B. (2017) 'The application of augmented reality technologies for the improvement of occupational safety in an industrial environment', Computers in Industry, 85, pp. 1-10. doi: 10.1016/j.compind.2016.11.004.

Teicholz, P. (2013) Labor-Productivity Declines in the Construction Industry: Causes and Remedies (a second look), AECbytes Viewpoint. Available at: http://www.aecbytes.com/viewpoint/2013/issue_67.html.

Thomas, B. et al. (2000) 'ARQuake: An Outdoor/Indoor Augmented Reality First Person Application', Personal and Ubiquitous Computing, 6(1), pp. 75-86. doi: 10.1007/s007790200007.

Thomas, B. H. and Sandor, C. (2009) 'What wearable augmented reality can do for you', IEEE Pervasive Computing, 8(2), pp. 8-11. doi: 10.1109/MPRV.2009.38.

Toossi, M. (2015) 'Labor force projections to 2024: the labor force is growing, but slowly', Monthly Labor Review. US Bureau of Labor Statistics, 2015(12). doi: 10.21916/mlr.2015.48.

Tumler, J. et al. (2008) 'Mobile augmented reality in industrial applications: approaches for solution of user-related issues', in Proceedings - 7th IEEE International Symposium on Mixed and Augmented Reality 2008, ISMAR 2008, pp. 87-90. doi: 10.1109/ISMAR.2008.4637330.

U.S. Department of Commerce (2017) Bureau of Economic Analysis. Available at: https://www.bea.gov/iTable/iTable.cfm?reqid=51\&step=51\&isuri=1\&5114=a\&5102=1\#reqid=51\&step=51\&isuri=1 $\& 5114=\mathrm{a} \& 5102=1$ (Accessed: 26 September 2017).

Wang, X. and Love, P. E. D. (2012) 'BIM + AR: Onsite information sharing and communication via advanced visualization', in Proceedings of the 2012 IEEE 16th International Conference on Computer Supported Cooperative Work in Design, CSCWD 2012. IEEE, pp. 850-855. doi: 10.1109/CSCWD.2012.6221920.

Watson, M. (2012) 'Concerns for Skills Shortages in the 21st Century: A Review into the Construction Industry, Australia', Australasian Journal of Construction Economics and Building, 7(1), pp. 45-54. Available at: http://epress.lib.uts.edu.au/journals/index.php/ajceb/article/view/2977 (Accessed: 22 September 2017).

Webel, S. et al. (2013) 'An augmented reality training platform for assembly and maintenance skills', Robotics and Autonomous Systems. North-Holland, 61(4), pp. 398-403. doi: 10.1016/j.robot.2012.09.013.

Williams, G. et al. (2015) 'BIM2MAR: An Efficient BIM Translation to Mobile Augmented Reality Applications', Journal of Management in Engineering, 31(1), p. A4014009. doi: 10.1061/(ASCE)ME.1943-5479.0000315.

Yan, W., Culp, C. and Graf, R. (2011) 'Integrating BIM and gaming for real-time interactive architectural visualization', Automation in Construction, 20(4), pp. 446-458. doi: 10.1016/j.autcon.2010.11.013.

Zollmann, S. et al. (2014) 'Augmented reality for construction site monitoring and documentation', Proceedings of the IEEE, 102(2), pp. 137-154. doi: 10.1109/JPROC.2013.2294314. 